\title{
Alternative parameters for echocardiographic assessment of fetal diastolic function
}

P. Zielinsky, L.H. Nicoloso,

C. Firpo, S. Marcantonio, M. Scheid, E.I. Gus,

A.L. Piccoli, F. Satler,

J.L. Manica, J. Zanettini and R.T. Cardoso
Unidade de Cardiologia Fetal, Instituto de Cardiologia do Rio Grande do Sul, Porto Alegre, RS, Brasil

\author{
Correspondence \\ P. Zielinsky \\ Unidade de Cardiologia Fetal \\ Instituto de Cardiologia do \\ Rio Grande do Sul \\ Av. Princesa Isabel, 395 \\ 90620-001 Porto Alegre, RS \\ Brasil \\ Fax: +55-51-3230-3637 \\ E-mail: zielinsky@cardiol.br or \\ pesquisa@cardnet.tche.br
}

Received May 9, 2003

Accepted October 30, 2003

\begin{abstract}
Alternative methods to assess ventricular diastolic function in the fetus are proposed. Fetal myocardial hypertrophy in maternal diabetes was used as a model of decreased left ventricular compliance (LVC), and fetal respiratory movements as a model of increased LVC. Comparison of three groups of fetuses showed that, in 10 fetuses of diabetic mothers (FDM) with septal hypertrophy (SH), the mean excursion index of the septum primum (EISP) (ratio between the linear excursion of the flap valve and the left atrial diameter) was $0.36 \pm 0.09$, in 8 FDM without SH it was $0.51 \pm 0.09(\mathrm{P}=0.001)$, and in the 8 normal control fetuses $(\mathrm{NCF})$ it was $0.49 \pm 0.12(\mathrm{P}=0.003)$. In another study, 28 fetuses in apnea had a mean EISP of $0.39 \pm 0.05$ which increased to $0.57 \pm 0.07$ during respiration $(\mathrm{P}<0.001)$. These two studies showed that the mobility of the septum primum was reduced when LVC was decreased and was increased when LVC was enhanced. Mean pulmonary vein pulsatility was higher in $14 \mathrm{FDM}(1.83 \pm 1.21)$ than in $26 \mathrm{NCF}$ $(1.02 \pm 0.31 ; P=0.02)$. In the same fetuses, mean left atrial shortening was decreased $(0.40 \pm 0.11)$ in relation to NCF $(0.51 \pm 0.09 ; \mathrm{P}=$ 0.011 ). These results suggest that FDM may have a higher preload than normal controls, probably as a result of increased myocardial mass and LV hypertrophy. Prenatal assessment of LV diastolic function by fetal echocardiography should include analysis of septum primum mobility, pulmonary vein pulsatility, and left atrial shortening.
\end{abstract}

\section{Key words}

- Fetal echocardiography

- Fetal diastolic function

- Prenatal diagnosis

- Septum primum mobility

- Fetal pulmonary vein flow

\section{Introduction}

The fetal circulation has four major communications between the systemic and pulmonary pathway: the foramen ovale, the ductus arteriosus, the ductus venosus, and the placenta. The saturated blood from the um- bilical vein reaches the heart through a triphasic high velocity flow in the ductus venosus, which goes directly to the left heart across the oval fossa, stretching the septum primum towards the left atrial cavity in late diastole. The low volume flow from the pulmonary veins to the left atrium occurs throughout the 
cardiac cycle, with a systolic peak, a diastolic peak, and presystolic flow during atrial contraction.

Ventricular diastole is a very complex phenomenon whose main components are relaxation, compliance, myocardial rigidity, and elastic recoil (1). Relaxation is an active process occurring with energy consumption in the early ventricular filling, when the myocardial fibers return to their original state after ventricular contraction (2-4). Compliance is a passive process occurring during late ventricular filling and atrial contraction, and is related to fiber distensibility. Myocardial rigidity is the contrary of ventricular compliance (5) and elastic recoil is a continuing decrease in ventricular pressure in early diastole (3).

Studies of diastolic function in adults using M-mode and Doppler echocardiography have shown the usefulness of unidimensional assessment of left atrial dynamics (6), atrioventricular (7-9) and pulmonary vein flow analysis (10-14) and, more recently, of tissue Doppler of atrioventricular rings and ventricular septum (15).

Classical echocardiographic assessment of fetal diastolic function uses Doppler analysis of mitral and tricuspid inflow waves. The waveforms obtained in diastole by pulsed Doppler echocardiography at the tip of both atrioventricular valves are biphasic, with an E wave representing early ventricular filling velocity, and an A wave related to flow velocity during atrial contraction in presystole. The normal E/A ratio during pregnancy is below 1 , which means that the fetal myocardium is relatively "stiff" compared to that of newborns and older children (16-22). An increase or inversion of the E/A ratio is related to ventricular diastolic dysfunction (23-27). There are few reports of other parameters used to evaluate ventricular diastolic function in the fetus.

In the present study, alternative methods are considered to assess ventricular diastolic function during fetal life using models of decreased ventricular compliance and increased ventricular filling. Specifically, we tested the hypotheses that: a) septum primum mobility is decreased in fetuses with decreased left ventricular compliance as a result of left ventricular hypertrophy in maternal diabetes and is increased during fetal respiratory movements, when the compliance of the left ventricle is increased; b) the mobility of the septum primum does not depend on the diameter of the foramen ovale; c) the global shortening of the left atrium is decreased in fetuses of diabetic mothers, and d) pulsatility of the pulmonary veins is increased during fetal life in diabetic pregnancies.

\section{Patients and Methods}

Four transversal and controlled studies were designed.

To assess the diastolic mobility of the septum primum, we measured its "excursion index" (EI), which is the ratio between the maximal linear displacement of the atrial flap valve and the left atrial diameter (28) in a four-chamber view (Figure 1). In the model of decreased left ventricular compliance, we compared the EI in 10 fetuses of diabetic mothers with septal hypertrophy and a mean gestational age of 34.8 weeks (32-39 weeks), 8 fetuses of diabetic mothers with normal septal thickness and mean gestational age of 34.0 weeks (32-38 weeks) and 8 normal fetuses of mothers without diabetes (controls) and a mean gestational age of 34.3 weeks (32-39 weeks). In the model of increased left ventricular compliance, 28 fetuses from 25 to 35 weeks of gestation were studied in apnea and during respiratory movements and the EI of the flap valve was compared in these two behavioral states.

The correlation between the EI of the atrial flap valve and the foramen ovale diameter was assessed in 102 normal fetuses from 20 to 38 weeks of gestation whose mothers did not show any evidence of systemic disease. 
The left atrial global shortening fraction (LASF) and the pulmonary vein pulsatility index (PVPI) were assessed in 14 fetuses of diabetic mothers and in 26 fetuses of normal control mothers. Mean gestational age was $31.7 \pm 3.8$ weeks for the diabetic mothers and $29.4 \pm 0.19$ weeks for the control group. LASF was obtained by the M-mode ratio: maximal left atrial diameter (telesystolic) - minimal left atrial diameter (presystolic)/maximal left atrial diameter (Figure 2), and PVPI by the Doppler ratio: peak systolic velocity - peak presystolic velocity/mean velocity in the pulmonary venous flow (Figure 3).

Data were analyzed statistically by ANOVA and by the Student $t$-test, with a critical $\mathrm{P}$ value of 0.05 , and correlations were calculated by the Pearson coefficient.

\section{Results}

Comparison of the three groups in the first study showed that EI was $0.36 \pm 0.09$ (0.30-0.43) in fetuses of diabetic mothers with septal hypertrophy, $0.51 \pm 0.09$ (0.39$0.59 ; \mathrm{P}=0.001$ ) in fetuses of diabetic mothers without septal hypertrophy, and $0.49 \pm$ 0.12 in control fetuses $(0.44-0.59 ; \mathrm{P}=0.003$; Figure 4). In the model of fetal breathing movements, fetuses in apnea had a mean EI of the flap valve of $0.39 \pm 0.05(0.29-0.48)$, which increased to $0.57 \pm 0.07$ during respiration (0.45-0.69; $\mathrm{P}<0.001)$.

There was no correlation between the excursion of the septum primum and the diameter of the foramen ovale $(r=-0.03)$ in the normal series examined for this parameter.

The gestational age of fetuses of diabetic mothers and of normal control fetuses in the third and fourth studies was not statistically different. Mean LASF was decreased $(0.40 \pm$ 0.11 ) [0.12 to 0.69$]$ in comparison to the control group $(0.51 \pm 0.09)$ [0.07 to 0.68 ] $(\mathrm{P}=0.011)$. Mean PVPI was higher $(1.83 \pm$ 1.21) [1.0 to 4.07] in fetuses of diabetic mothers than in normal control fetuses (1.02 \pm 0.31) [0.53 to 1.67] $(\mathrm{P}=0.02)$.

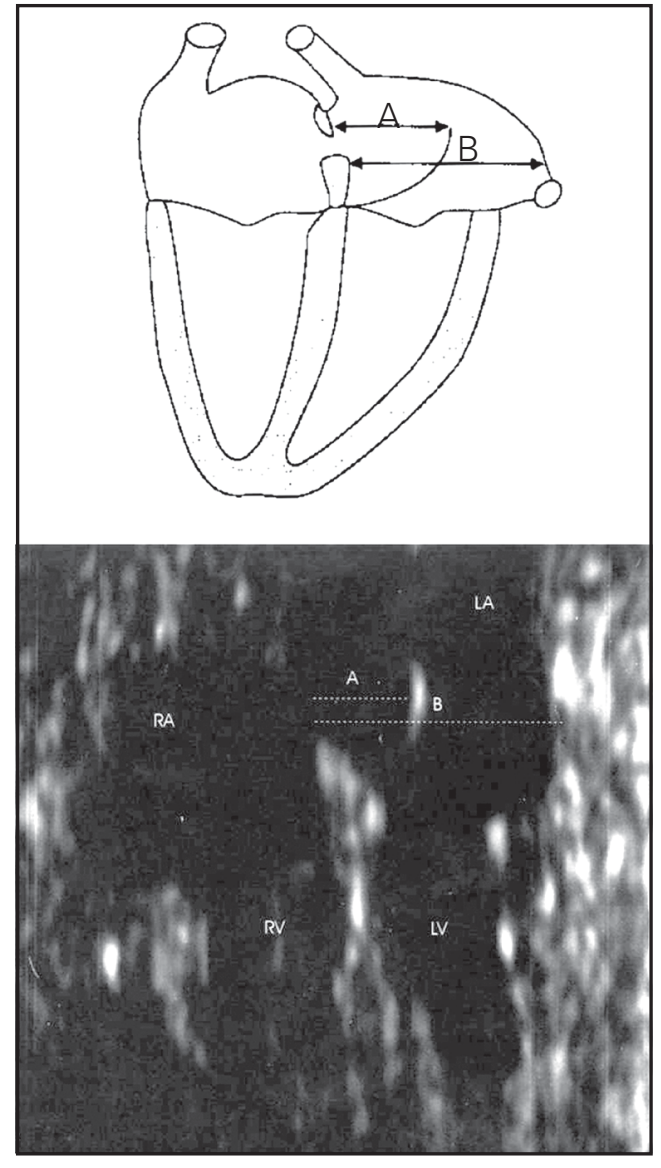

Figure 1. Diagram showing how the excursion index of the septum primum is obtained from the ratio $A / B$. $A$ is the maximal diastolic excursion of the flap valve, in a four-chamber view, and $B$ the maximal left atrial diameter. $R A, L A=$ right and left atrium, respectively; $\mathrm{RV}, \mathrm{LV}=$ right and left ventricle, respectively.

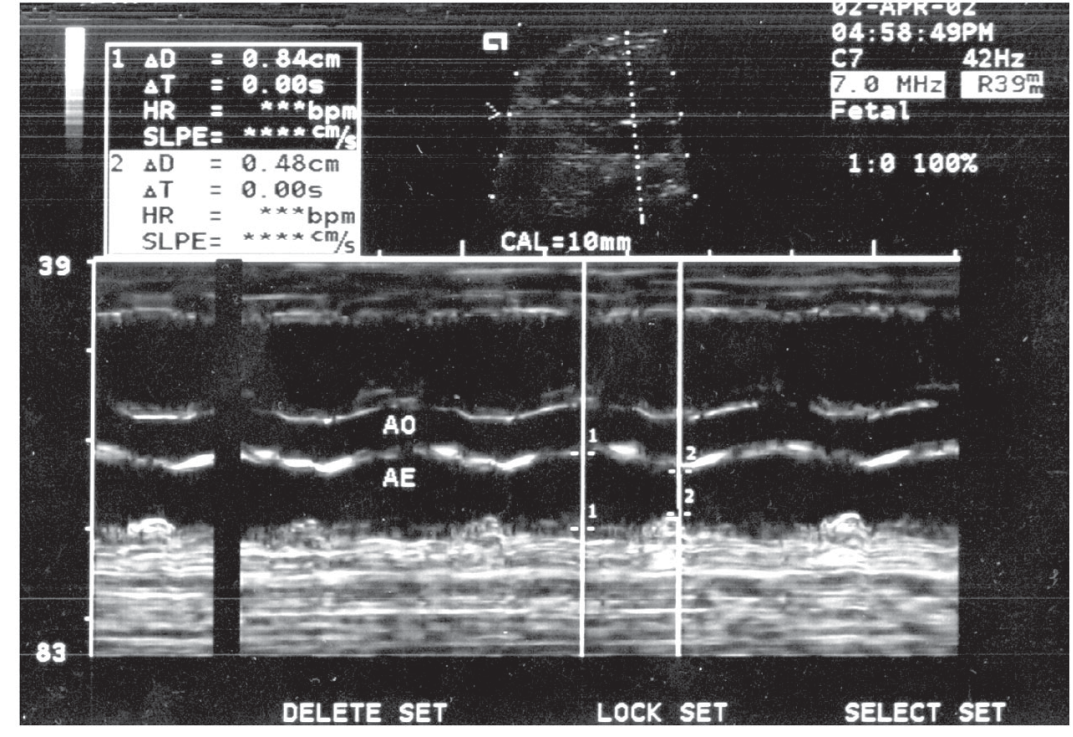

Figure 2. M-mode echocardiographic measurement of the left atrial shortening fraction. 1 , Left atrial maximal diameter (telesystolic); 2, left atrial minimal diameter (presystolic). The shortening fraction is obtained from the ratio (maximal diameter - minimal diameter)/ maximal diameter. 


\section{Discussion}

This report provides new insights on the echocardiographic assessment of fetal diastolic function. Some of the data discussed here are part of an ongoing research protocol aimed at determining the usefulness of alternative methods for the evaluation of normal

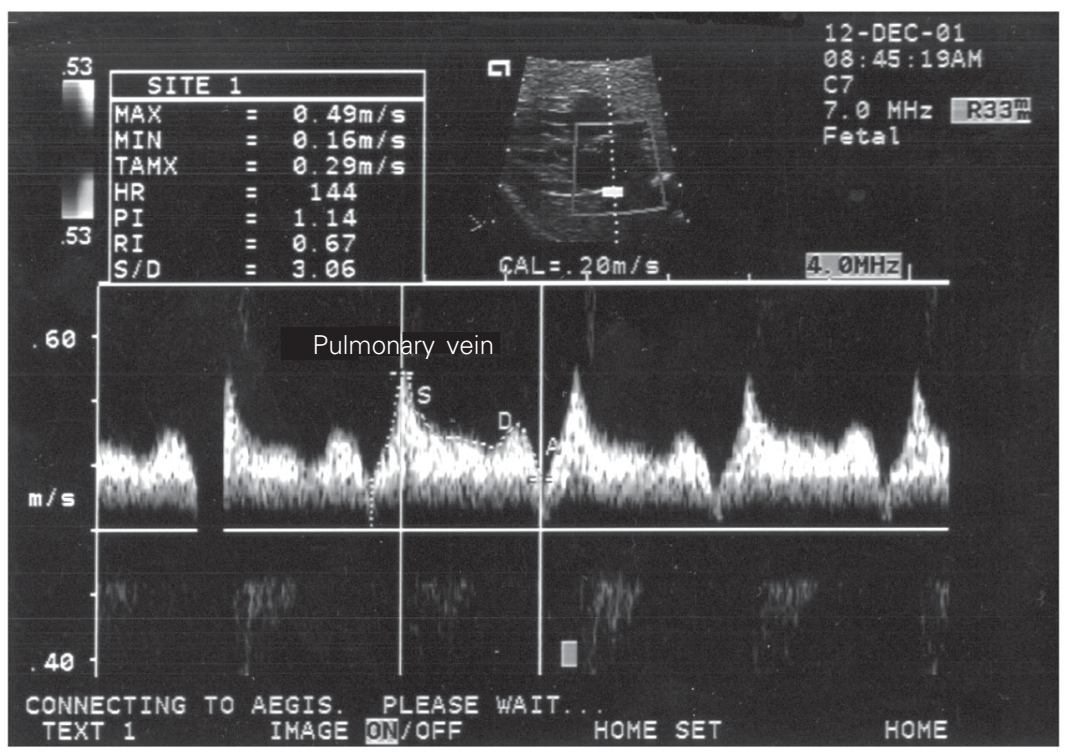

Figure 3. Doppler tracing of the pulmonary vein. $A=$ presystolic peak; $D=$ diastolic peak; $S$ $=$ systolic peak. The pulsatility index is obtained from the ratio (maximal velocity [systolic or diastolic] - presystolic peak)/mean velocity. The mean velocity is automatically calculated by the instrument as the area below the manual tracing of the waveform during the entire cardiac cycle.

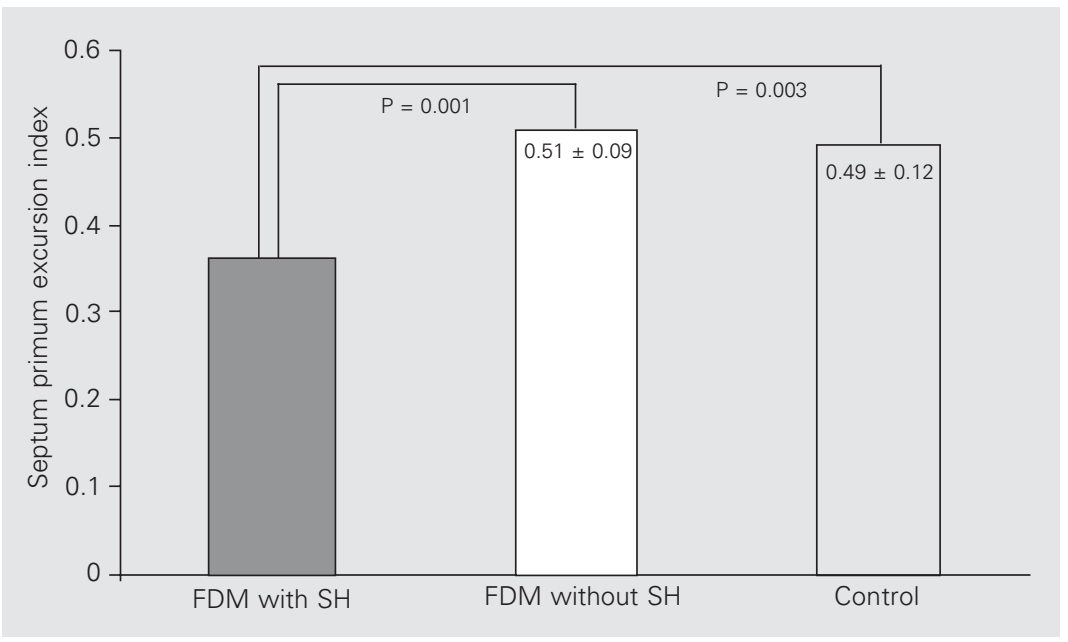

Figure 4. Comparison of the mean excursion index of the septum primum of fetuses of diabetic mothers (FDM) with and without septal hypertrophy (SH) and of the normal control group. The statistical test used was ANOVA. and abnormal events occurring during fetal ventricular diastole.

It was shown that septum primum mobility behaves differently in situations in which the ventricular compliance is reduced, such as in myocardial hypertrophy secondary to maternal diabetes (with a decrease in linear diastolic displacement) or enhanced, such as during fetal breathing (with an increase in displacement within the left atrium). We suggest that the increase in left atrial diastolic pressure as a result of the less compliant hypertrophic left ventricle interferes with the normal mobility of the atrial flap valve, limiting its expansion. On the other hand, during respiratory movements it has already been demonstrated that there is an increase in left ventricular compliance (29) which may cause a decrease in left atrial diastolic pressure and ultimately an increase in septum primum excursion. The measurement of the EI of the atrial flap valve is easy (28). It was also determined that the excursion of the flap valve does not depend on the diameter of the interatrial communication.

Studies carried out on adults have shown that the dynamics of the left atrial walls is related to left ventricular compliance, especially in patients with hypertrophic cardiomyopathy (6). Thus, the LASF appears to be dependent on the left ventricle preload and to be proportional to ventricular compliance (6). We tested the hypothesis that the fetal LASF would be decreased in fetuses of diabetic mothers compared to fetuses of normal control mothers. The results obtained so far are compatible with this assumption, probably as a result of increased myocardial mass and left ventricular hypertrophy in fetuses of diabetic mothers (30).

This study also showed that the PVPI is increased in fetuses of diabetic mothers in relation to fetuses of mothers with normal glucose levels. It is suggested that this could be due to the less compliant fetal left ventricle in diabetic pregnancies, with myocardial hypertrophy and increase in left atrial 
pressure, with a relatively restricted emptying of the pulmonary vein flow $(31,32)$.

The assessment of pulmonary vein pulsatility and left atrial shortening is an alternative method to evaluate diastolic function in fetuses. This is important because diastolic dysfunction, mainly related to decreased left ventricular compliance in fetuses of diabetic mothers, may be the cause of neonatal heart failure and transient tachypnea, and even when causing no symptoms it may increase the morbity and mortality of these fetuses when detected in late pregnancy.

Other methods to evaluate fetal ventricular diastolic function, still in an early stage of investigation, are the analysis of the flow across the ductus venosus and the foramen ovale as well as tissue Doppler motion anal- ysis of the ventricular walls. As the foramen ovale acts anatomically and functionally like a vessel, it would be possible to document alterations in its flow through the pulsatility index. The pulsatility index of the foramen ovale has been measured by placing the Doppler sample volume in the foramen ovale and calculating the ratio (peak systolic velocity peak presystolic velocity/mean velocity). The results obtained by this method are still being analyzed.

The use of the alternative parameters described here to assess fetal left ventricular diastolic function in clinical practice and routine fetal echocardiography must be thoroughly evaluated in additional studies in order to determine its accuracy and reproducibility.

\section{References}

1. Nishimura RA, Housmans PR, Hatle LK \& Tajik AJ (1989). Assessment of diastolic function of the heart: background and current applications of Doppler echocardiography. Part I. Physiologic and pathophysiologic features. Mayo Clinic Proceedings, 64: 71-81.

2. Labovitz AJ \& Pearson AC (1987). Evaluation of left ventricular diastolic function: Clinical relevance and recent Doppler echocardiographic insights. American Heart Journal, 114: 836-851.

3. Grossman W \& McLaurin LP (1976). Diastolic properties of the left ventricle. Annals of Internal Medicine, 84: 316-326.

4. Yamamoto K, Redfield MM \& Nishimura RA (1996). Analysis of left ventricular diastolic function. Heart, 75: 27-35.

5. Mirsky I (1976). Assessment of passive elastic stiffness of cardiac muscle: mathematical concepts, physiologic and clinical considerations, directions of future research. Progress in Cardiovascular Disease, 18: 277-308.

6. Briguori C, Betocchi S, Losi MA, Manganelli F, Piscione F, Pace L, Boccalatte M, Gottilla R, Salvatore M \& Chiariello M (1998). Noninvasive evaluation of left ventricular diastolic function in hypertrophic cardiomyopathy. American Journal of Cardiology, 81: 180-187.

7. Yellin EL, Meisner JS, Nikolic SD \& Keren G (1992). The scientific basis for the relations between pulsed-Doppler transmitral velocity patterns and left heart chamber properties. Echocardiography, 9: 313-338.

8. Appleton CP, Galloway JM, Gonzales MS, Gaballa M \& Basnight MA (1993). Estimation of left ventricular filling pressures using twodimensional and Doppler echocardiography in adult patients with cardiac disease. Journal of the American College of Cardiology, 22: 1972-1982.

9. Little WC, Warner JG, Rankin KM, Kitzman DW \& Chen C (1998). Evaluation of left ventricular diastolic function from the pattern of left ventricular filling. Clinical Cardiology, 21: 5-9.

10. Keren G, Sherez J, Megidish R, Levitt B \& Laniado S (1985). Pulmo- nary venous flow pattern - its relationship to cardiac dynamics. A pulsed Doppler echocardiographic study. Circulation, 71: 1105-1112.

11. Schiavone WA, Calafiore PA \& Salcedo EE (1989). Transesophageal Doppler echocardiographic demonstration of pulmonary venous flow velocity in restrictive cardiomyopathy and constrictive pericarditis. American Journal of Cardiology, 63: 1286-1288.

12. Nishimura RA, Abel MD, Hatle LK \& Tajik AJ (1990). Relation of pulmonary vein to mitral flow velocities by transesophageal Doppler echocardiography - effect of different loading conditions. Circulation, 81: 1488-1497.

13. Kuecherer HF, Kusumoto F, Muhiudeen IA, Cahalan MK \& Schiller NB (1991). Pulmonary venous flow patterns by transesophageal pulsed Doppler echocardiography: relation to parameters of left ventricular systolic and diastolic function. American Heart Journal, 122: $1683-1693$.

14. Rossvoll O \& Hatle LK (1993). Pulmonary venous flow velocities recorded by transthoracic Doppler ultrasound: relation to left ventricular diastolic pressures. Journal of the American College of Cardiology, 21: 1687-1696.

15. Miyatake K, Yamagishi M, Tanaka N, Uematsu M, Yamazaki N, Mine $Y$, Sano A \& Hirama M (1995). A new method for evaluation of left ventricular wall motion by color-coded tissue Doppler echocardiography: in vitro and in vivo studies. Journal of the American College of Cardiology, 25: 717-724.

16. Reed KL, Sahn DJ, Scagnelli S, Anderson CF \& Shenker L (1986). Doppler echocardiographic studies of diastolic function in the human fetal heart: changes during gestation. Journal of the American College of Cardiology, 8: 391-395.

17. van der Mooren K, Barendregt LG \& Wladimiroff JW (1991). Fetal atrioventricular and outflow tract flow velocity waveforms during normal second half of pregnancy. American Journal of Obstetrics and Gynecology, 165: 668-674. 
18. Carceller-Blanchard AM \& Fouron JC (1993). Determinants of the Doppler flow velocity profile through the mitral valve of the human fetus. British Heart Journal, 70: 457-460.

19. Tulzer G, Khowsathit P, Gudmundsson S, Wood DC, Tian ZY, Schmitt K \& Huhta JC (1994). Diastolic function of the fetal heart during the second and third trimester: a prospective longitudinal Doppler-echocardiographic study. European Journal of Pediatrics, 153: 151-154.

20. van Splunder P, Stijnen T \& Wladimiroff JW (1996). Fetal atrioventricular flow-velocity waveforms and their relation to arterial and venous flow-velocity waveforms at 8 to 20 weeks of gestation. Circulation, 94: 1372-1378.

21. Weber HS (1996). Serial echocardiographic Doppler evaluation of diastolic function in the normal human fetus. Cardiology in the Young, 6: 32-36.

22. Weiner Z, Efrat Z, Zimmer EZ \& Itskovitz-Eldor J (1997). Fetal atrioventricular blood flow throughout gestation. American Journal of Cardiology, 80: 659-662.

23. Rizzo G, Arduini D, Romanini C \& Mancuso S (1988). Doppler echocardiographic assessment of atrioventricular velocity waveforms in normal and small-for-gestational-age fetuses. British Journal of Obstetrics and Gynaecology, 95: 65-69.

24. Harada K, Rice MJ, McDonald RW, Shiota T, Ishii M, Reller MD \& Sahn DJ (1997). Doppler echocardiographic evaluation of ventricular diastolic filling in fetuses with ductal constriction. American Journal of Cardiology, 79: 442-446.
25. Harada K, Rice MJ, Shiota T, Ishii M, McDonald RW, Reller MD \& Sahn DJ (1997). Gestational age- and growth-related alterations in fetal right and left ventricular diastolic filling patterns. American Journal of Cardiology, 79: 173-177.

26. Tsyvian P, Malkin K, Artemieva O \& Wladimiroff JW (1998). Assessment of left ventricular filling in normally grown fetuses, growthrestricted fetuses and fetuses of diabetic mothers. Ultrasound in Obstetrics and Gynecology, 12: 33-38.

27. Veille JC, Smith N \& Zaccaro D (1999). Ventricular filling patterns of the right and left ventricles in normally grown fetuses: a longitudinal follow-up study from early intrauterine life to age 1 year. American Journal of Obstetrics and Gynecology, 180: 849-858.

28. Firpo C \& Zielinsky P (1998). Mobility of the flap valve of the primary atrial septum in the developing human fetus. Cardiology in the Young, 8: 67-70.

29. Miyague N, Ghidini A \& Miyague L (1997). Fetal breathing movements are associated with changes in compliance of the left ventricle. Fetal Diagnosis and Therapy, 12: 72-75.

30. Menezes HS, Barra M, Belló AR, Martins CB \& Zielinsky P (2001). Fetal myocardial hypertrophy in an experimental model of gestational diabetes. Cardiology in the Young, 11: 609-613.

31. Hong YM \& Choi JY (2000). Pulmonary venous flow from fetal to neonatal period. Early Human Development, 57: 95-103.

32. Crowe DA \& Allan LD (2001). Patterns of pulmonary venous flow in the fetus with disease of the left heart. Cardiology in the Young, 11 : 369-374. 